\title{
EDITORIAL
}

\section{Examining the conceptual and scientific underpinnings of research in developmental psychopathology}

\author{
DANTE CICCHETTI ${ }^{a}$ AND JOHN E. RICHTERS ${ }^{b}$ \\ ${ }^{a}$ Mt. Hope Family Center, University of Rochester; ${ }^{b}$ Child \& Adolescent Disorders, \\ Research Branch, National Institute of Mental Health
}

The interdisciplinary science of developmental psychopathology has evolved from its historical roots in a variety of fields including: sociology; epidemiology; embryology; the neurosciences and psychobiology; psychoanalysis; clinical, developmental, and experimental psychology; and psychiatry (Cicchetti, 1990) into an increasingly mature integrative framework within which the contributions of these heretofore largely separate disciplines could be fully realized within the broader context of understanding individual development and functioning, both normal and abnormal (see chapters in Cicchetti \& Cohen, 1995a, 1995b; see also Cicchetti \& Toth, in press). In one of the early statements concerning the goals of this field, Cicchetti (1990) asserted that: "Developmental psychopathology ... should bridge fields of study, span the life cycle, and aid in the discovery of important new truths about the processes underlying adapta-

The opinions expressed herein are those of the authors and do not necessarily represent the position of the National Institute of Mental Health. Dante Cicchetti's work on this Special Issue was supported by a grant from the Spunk Fund, Inc. We thank the contributors to this Special Issue for their dedication and commitment to this project and for their continuing contributions to the field.

Address correspondence and reprint requests to: Dante Cicchetti, Ph.D., Mt. Hope Family Center, 187 Edinburgh Street, Rochester, NY 14608 or John E. Richters, Ph.D., Child and Adolescent Disorders, Research Branch, NIMH, 5600 Fishers Lane, Room 10-104, Rockville, MD 20857. tion and maladaptation, as well as the best means of preventing or ameliorating psychopathology. Moreover, this discipline should contribute greatly to reducing the dualisms that exist between the clinical study of and research into childhood and adult disorders, between the behavioral and biological sciences, between developmental psychology and psychopathology, and between basic and applied science" (p. 20).

Since the publication of two landmark works in the field, Rutter and Garmezy's (1983) chapter in the Handbook of Child Psychology and the Special Issue of Child Development (Cicchetti, 1984), the life span study of psychopathology has developed rapidly during the closing decades of the 20th century. For example, the developmental psychopathology perspective has played an influential role in enhancing our understanding of the incidence and prevalence rates, as well as the origins, course, and sequelae, of high-risk conditions and mental disorder (see chapters in: Cicchetti \& Cohen, 1995a, 1995b; Lenzenweger \& Haugaard, 1996; and Matthysse, Levy, Kagan, \& Benes, 1996; see also Institute of Medicine, 1989; Richters \& Cicchetti, 1993). Moreover, in 1987 a symposium on developmental psychopathology was initiated, with each conference resulting in a subsequent publication devoted to the thematic topic for that meeting. To date, seven volumes have appeared in the literature (for the most 
recent, see Cicchetti \& Toth, 1996). Indeed, this has been a period of dramatic knowledge gains in the multiple domains of child and adult development, with an emphasis on increasingly specific process-level models of normal and abnormal development, an acknowledgment that multiple pathways exist to the same outcome and that the effects of one component's value may vary in different systems, and an intensification of interest in biological and genetic factors, as well as in social and contextual factors related to the development of maladaptation and psychopathology.

Additionally, in recognition of this young field's scientific achievements, the Steering Committee of the Institute of Medicine adopted the principles of developmental psychopathology as the organizing framework for its report entitled Research on Children and Adolescents with Mental, Behavioral, and Developmental Disorders (Institute of Medicine, 1989). Likewise, the National Institute of Mental Health's National Plan for Research on Child and Adolescent Mental Disorders (National Advisory Mental Health Council, 1990), an outgrowth of the work of the Institute of Medicine's (1989) report, embraced developmental psychopathology as its overarching paradigm for organizing future research priorities in the field of child and adolescent disorders. Moreover, the National Research Council (1993) advocated the adoption of an ecological-developmental perspective (see Belsky, 1993; Cicchetti \& Lynch, 1993) to examine the factors within society, the family, and the child that can exacerbate or mitigate the deleterious consequences of child maltreatment. Furthermore, the Institute of Medicine (1994) highlighted developmental psychopathology as one of four core sciences considered to be essential to expand the frontiers of prevention and intervention efforts into reducing the risk factors for mental disorders and their sequelae throughout the life course.

Perhaps because of these accomplishments, the past decades also have been a period wherein penetrating questions have been asked about the adequacy of existing methods and assessment strategies for addressing the pressing research issues that lie ahead in the upcoming millennium. As researchers, we are socialized through training and practice into very specialized subcultures, not infrequently narrowly defined by established values, priorities, assumptions, and ways of thinking about important issues. Accordingly, the phenomena we study, the manner in which they are conceptualized, the research methods we employ, and the ways we analyze and interpret our data commonly seem to be the obvious choices. In fact, it is often difficult to recognize that consequential choices are even being made.

Because by nature of its primary foci developmental psychopathology is a dynamic and evolving field, we believe that, despite its youth, this is a ripe time for self-reflection. The goal of developmental psychopathology is not to exercise hegemony over research into risk and psychopathology. Hence, our field cannot afford to become paradigm bound or to exhibit premature closure concerning how to investigate the links between normal and abnormal development. Thus, whereas most Special Issues of Development and Psychopathology are devoted to a consideration of explicit theories and empirical claims, this Issue is devoted instead to the equally powerful implicit assumptions that influence our mainstream research projects. Contributors were asked to examine fundamental assumptions and practices in developmental psychopathology research, the impasses and impediments to progress that have been created as a result, and to provide constructive solutions for shaping the nature and direction of future research efforts in the field.

Papers in this issue address a broad range of assumptions that have contributed to the nature of the current investigations that have been conducted in the field of developmental psychopathology and that must be examined to ensure that the field moves beyond its current confines. Despite the many issues that have been raised in this collection of papers, at least that many and more remain. We challenge you to examine the implicit and explicit assumptions that guide your work, and to devise constructive solutions to these potential impediments. 


\section{References}

Belsky, J. (1993). Etiology of child maltreatment: A developmental-ecological analysis. Psychological Bulletin, 114, 413-434.

Cicchetti, D. (Ed.) (1984). Developmental psychopathology [Special Issue]. Child Development, 55(1), 1314.

Cicchetti, D. (1990). An historical perspective on the discipline of developmental psychopathology. In J. Rolf, A. Masten, D. Cicchetti, K. Nuechterlein, and S. Weintraub (Eds.), Risk and protective factors in the development of psychopathology (pp. 2-28). New York: Cambridge University Press.

Cicchetti, D., \& Cohen, D. (Eds.) (1995a). Developmental psychopathology: Vol. 1. Theory and method. New York: Wiley.

Cicchetti, D., \& Cohen, D. (Eds.) (1995b). Developmental psychopathology: Vol. 2. Risk, disorder, and adaptation. New York: Wiley.

Cicchetti, D., \& Lynch, M. (1993). Toward an ecological/ transactional model of community violence and child maltreatment: Consequences for children's development. Psychiatry, 56, 96-118.

Cicchetti, D., \& Toth, S. L. (in press). Perspectives on research and practice in developmental psychopathology. In W. Damon (Series Ed.), Handbook of child psychology (Vol. 4, 5th ed.). New York: Wiley.

Cicchetti, D., \& Toth, S. L. (Eds.) (1996). Rochester symposium on developmental psychopathology: Vol. 7. Adolescence: Opportunities and challenges. Rochester, NY: University of Rochester Press.
Institute of Medicine (1989). Research on children and adolescents with mental, behavioral, and developmental disorders. Washington, DC: National Academy Press.

Institute of Medicine (1994). Reducing risks for mental disorders: Frontiers for preventive intervention research. Washington, DC: National Academy Press.

Lenzenweger, M., \& Haugaard, J. (Eds.) (1996). Frontiers of developmental psychopathology. New York: Oxford University Press.

Matthysse, S., Levy, D., Kagan, J., \& Benes, F. (Eds.) (1996). Psychopathology: The evolving science of mental disorder. New York: Cambridge University Press.

National Advisory Mental Health Council (1990). National plan for research on child and adolescent mental disorders. Rockville, MD: U.S. Department of Health and Human Services (Publication 90-1683).

National Research Council (1993). Understanding child abuse and neglect. Washington, DC: National Academy Press.

Richters, J., \& Cicchetti, D. (Eds.) (1993). Toward a developmental perspective on conduct disorder [Special Issue]. Development and Psychopathology, 5(1/2), 1344.

Rutter, M., \& Garmezy, N. (1983). Developmental psychopathology. In P. Mussen (Series Ed.), Handbook of child psychology (Vol. IV, 4th ed., pp. 774-911). New York: Wiley. 